OUTSIDE EUROPE

\title{
Medical Problems of Developing Nations: An Attempt to Bring Medical Care to Rural Communities in Iran
}

\author{
HOSSHYN A. RONAGHY,* M.D. ; KHOSROW NASR,, M.D.
}

Despite great scientific advances in medicine a large section of society, primarily rural, still receives poor medical care; the Western countries are no exception ${ }^{1-10}$. Before medical care in rural areas can be improved three problems must be considered: the actual provision of medical services; the quality of the latter; and finally the development of a system for continuing these services in the context of medical tradition. Medical tradition determines a certain standard, creates the framework of medical practice, and is self-pervetuating. In most developed countries a modern medical tradition has already evolved. It is not the purpose of this article to discuss these traditions and the manner in which they meet society's need for better medical care, but rather to point out that in the developing nations the concern is for the rapid delivery of good medical care based on a modern medical tradition.

\section{Resources Versus Tradition}

Considering the resources of some of the developing nations, it is not impossible for these communities to devise the means for making medical care and services rapidly available to many of their members. For example, a medical school curriculum could be devised to train a physician to care for the immediate needs of that community in the shortest possible time. Though a community with the necessary resources could resolve its immediate health problems in this way, it will have done so at the expense of higher quality and a worthwhile medical tradition. Few developing nations have a tradition of modern medicine, and, since forming one is one of their major tasks, any hindrance to such a development could have unfavourable long-term effects. Furthermore, since these nations are faced with the more acute problem of providing a large and generally uncared-for section of their population with medical services, their dilemma is increased.

Confronted with such problems here in Iran, we have devised some solutions for delivering medical care to rural communities. The larger cities with private and governmental health services form the smaller part of Iran's total population $(61.9 \%$ live in villages with fewer than 5,000 inhabitants), and their medical care problem will not be considered further in this article.

\section{Health Corps}

Iran has a total of 54,031 villages in an area of $1,600,000$ square kilometres. Of these 53,775 have a population of less than 2,500 and 23,652 less than 100 (Table I). Continuous medical care is therefore impracticable. To these logistic

*Assistant Professor of Medicine, Pahlavi University, Shiraz, Iran. problems can be added those of poor nutrition, lack of sanitation and an understanding of basic public health measures, a population explosion, and, finally, the inability of villages to support a doctor either socially or economically. At times these problems have seemed insurmountable.

TABLE I.-Population of Iran's Villages. (Total Village Population: $15,965,168$, or $61 \cdot 9 \%$ of Iran's Population.)

\section{Population \\ $2,501-5,000$ \\ $251-2,500$}

Less than 100

No. of Villages
256
14,627
15,496
23,652

On 21 January 1964, however, His Imperial Majesty declared that all Iranians were to have the benefits of medical care. The suggested manner of providing this care was unique. Young medical and paramedical personnel were to be employed for a temporary period; on 3 May 1964 Iran's Parlia. ment decreed that they were to be drafted into a Health Corps rather than into military service, as was then usual. The draftees included all eligible graduating doctors after a year of rotating internship, dentists, pharmacists, and certain qualified university and high-school graduates. For six months these people received training in public health and rural medicine as well as some basic military training. The instruction given included 345 hours of public health courses plus special courses in laboratory techniques, environmental health, health education, and dental care. The draftees spent the next 18 months in the villages. The doctors were given the rank of lieutenant, while others had military ranks according to their educational background.

The objectives of the Health Corps in a village are not only caring for the sick, but also preventing the spread of communicable diseases, maintaining basic health, and providing education in sanitation and nutrition, including family planning. In conjunction with other village programmes, such as the literacy corps, land reform, village co-operative, village council, and local elective judiciary systems, the final aim has been to create a healthier, better educated, happier, more productive, and more optimistic rural community which would in time become a self-sufficient entity within the nation.

\section{Mobile Units}

With these objectives, the members of the corps are organized in stationary and mobile units. A stationary unit, which consists of doctors, dentists, pharmacists, laboratory technicians, sanitary engineers, health instructors, nurses, and nutritionists, has an equipped base of operation covering an area with a radius of about 10 kilometres. These stationary units are further divided into smaller mobile units which consist of one doctor, two high-school graduates serving as assistants, medical supplies, and a vehicle for transport. Each 
subunit visits two villages a day, and each village once a week. At present there are 330 active mobile subunits, but their number has been limited by the number of graduating doctors. Recently their salaries have been increased and some have decided to extend their tenure for one to two years (96 did so in 1969). Furthermore, there is a plan to introduce women doctors, who have so far been exempt. Since mid1964, when the programme was implemented, 1,802 such mobile units have been sent to various villages, each for a period of 18 months. Their activities for this period are listed in Table II. In four years over 13 million patients have been seen by a doctor.

TABLE II.-Health Corps Activities Between 1964 and 1969 Type of Activity Outpatient visits Hospital referals Laboratory procedures . Vaccination Dental visits Number of medical films shown Mealth education conferences : Attendance Clinics constructed Water supply made sanitary or newly buil Slaughterhouses made sanitary or newly buil No 13,091,703 42,216
386,467 386,467
$6,148,107$ 348,107
345,659 7,615
$1,987,299$ $1,987,299$
24,580
$2,922,987$

216
13,409
245

\section{Extending Medical Care}

Increasingly, the Health Corps is introducing medical services into rural communities which had previously lacked any type of medical care. Furthermore, because of the system of rotation and limited service each young man in the corps has an enthusiasm which adds to the quality of the care. Finally, in creating a sense of individual responsibility towards patient care and community service in the members of the corps, we are laying a firm foundation for our developing medical tradition.

Despite the significant accomplishments of the Health Corps, all of Iran's medical care problems are not yet solved. Firstly, some of the larger communities are not at present benefiting from the activities of the Health Corps. Some of these towns have their private practising doctors but the overall level of care in these areas is poor because both enthusiasm and the necessary equipment and services are lacking. Secondly, the Health Corps attempts to provide only basic services and preliminary care. For more extensive care an intricate complex of centres is required. These centres would have to care for patients in hospital and provide more specialist laboratory, technical, and medical services. We hope and intend that the university will become the central axis of this medical complex.

\section{University Medical Centres}

At present Iran has seven medical schools. One is at Pahlavi University in Shiraz, the capital of the province of Fars (population 2.2 million). The medical school has two major hospitals in Shiraz, which care for both free and private patients; together the school and its hospitals are being developed as the major medical centre in Fars, while smaller hospital centres are being built throughout the province. The professional staff of these outlying hospitals are appointed by the university and are members of the appropriate university department. Periodically they come to the university, while the attending staff from the university medical centre regularly visit the outlying hospitals. The university will thus develop into a postgraduate training centre. The main academic department will continue to be at the university medical centre, and the workers at the outlying hospitals will be closely connected with the university in terms of their ap- pointments as well as the two-way exchange. On the other hand, the construction and maintenance of these outlying hospitals is not the university's responsibility. At present welfare organizations such as the Red Lion and Sun are the major benefactors, but in the future it is hoped that the community itself will be more directly concerned with these hospitals.

Finally, in a province such as Fars the Health Corps could function at the village level, but hospitals in nearby towns would have to provide more advanced services and continue to be the link with the university medical centre. Technicians, under the supervision of the university, manage the laboratory and radiological facilities. Consultations are readily available from the university and the chairman of the surgical department visits the hospital regularly. A summary of one year's activities is given in Table III. At present paediatric and medical services are being developed. It should be emphasized that this hospital has not only played a major medical part in one of Iran's poorest communities, but has also been a force in every aspect of this town's development.

TABLE III.-Borazjan Hospital. One Year's Activities Ending September Type of Activity

Clinic visits

Emergency-room visits

Operations:

in operating-rooms

with general anaesthesia

in emergency room 1968

\section{Conclusion}

With the establishment of the above hospital and two others, along with five more under construction or in the planning stage, it is hoped that the final link with the Health Corps will be made. Continuation and expansion of these programmes will eventually provide for a forgotten and uncared-for section of Iran's population. We believe that the participation of the university, through selecting and supervising professional staff, through implementing postgraduate training programmes, and, finally, providing more advanced services, will have an enormous effect on the quality of this medical care. Nevertheless, the university as the developer as well as the perpetuator of our developing medical tradition cannot be sacrificed to the immediate needs of the community, and the community itself must realize that only in strengthening the university will it continue to receive efficient medical care. We feel that the Pahlavi University Rural Medicine Programme not only reflects the need of the university continuously to evaluate its approach and ideas in an ever-changing society, but that it also reinforces the community's decision, through its financial support and cooperation, to stress the importance and the autonomy of the university.

We wish to thank the Office of the Health Corps, the Bureau of Statistics, and the Borazjan Hospital for providing data concerning their activities.

\section{REFERENCES}

1 Fuchs, V. R., New England fournal of Medicine, 1968, 279, 190. Izanec, J. J., Moggio, R. A., and Murray, A. J., New England fournal of Medicine, 1968, 279, 550 .

3 Lee, P. R., New England Fournal of Medicine, 1968, 279, 1139.

4 Lang, R. R., New England fournal of Medicine, 1968, 279, 163.

5 Marston, R. Q., New England Fournal of Medicine, 1968, 279, 520. Phillips, M. L., Mabry, J. H., and Houston, C. S., New England fournal of Medicine, 1968, 278, 1263.

7 Pizzo, P. A., New England fournal of Medicine, 1968, 279, 551. Saidi, F., XI Conference of the Persian Gulf Medica! Society, 1968, Tehran, Iran.

9 Warren, J. V., Annals of Internal Medicine, 1968, 69, 951.

10 Williams, G., New England fournal of Medicine, 1968, 279, 1031. 